03.4

\title{
Зондирование водогазонасыщенных насыпных сред переотраженными волнами непосредственно после воздействия ударной волны
}

\author{
() А.Т. Ахметов ${ }^{1}$, И.К. Гималтдинов ${ }^{2, \llbracket}$, М.А. Азаматов ${ }^{3}$, А.Ф. Мухаметзянов ${ }^{2}$, Д.Р. Богданов ${ }^{1}$ \\ ${ }^{1}$ Институт механики им. Р.Р. Мавлютова Уфимского фредерального исследовательского центра РАН, Уфа, Россия \\ ${ }^{2}$ Уфимский государственный нефртяной технический университет, Уфа, Россия \\ ${ }^{3}$ Салым Петролеум Девелопмент Н.В., Москва, Россия \\ "E-mail: iljas_g@mail.ru
}

Поступило в Редакцию 19 апреля 2021г.

В окончательной редакции 9 августа 2021 г.

Принято к публикации 21 сентября 2021 г.

\begin{abstract}
Исследована возможность использования переотраженных волн для зондирования насыпных водогазонасыщенных сред после воздействия ударной волны. Показаны результаты, полученные с использованием зондирующих импульсов.
\end{abstract}

Ключевые слова: насыпная среда, волна, водонасыщенность, ударная труба, пузырьки газа.

DOI: 10.21883/PJTF.2022.01.51874.18834

Интерес к задачам распространения ударных волн в насыщенных пористых средах связан с изучением эффективности временны́х защитных сооружений, вопросами сейсморазведки, моделирования хаммер-эффекта при гидроразрыве пласта и т.д. [1-6]. Экспериментальные работы по изучению волн в насыпных средах обычно проводятся в ударных трубах $[7,8]$. Традиционно ударные трубы используются для исследования особенностей распространения ударных волн в различных средах, анализа волновых свойств этих сред по скорости ударных волн и изменению формы импульса. В ударной трубе, оснащенной секцией насыпных сред, волна многократно переотражается от поверхности изучаемой пористой среды и верхнего торца трубы. Переотраженные волны можно использовать для изучения изменений в среде, произошедших под воздействием ударной волны, т. е. как зондирующие импульсы. Основная задача настоящей работы состоит в изучении возможности использования переотраженных волн для зондирования водогазонасыщенных насыпных сред непосредственно после воздействия ударной волны, а также в иллюстрации результатов, полученных при использовании зондирующих импульсов. Под зондированием в настоящей работе понимается выявление акустических свойств (изменения формы эпюр ударных импульсов и их скоростей).

Экспериментальные исследования проводились на ударной трубе [8], схематическое изображение которой приведено на вставке к рис. 1. Для регистрации импульсов давления использовались пьезоэлектрические датчики, значения давления разрыва фиксировались тензометрическим датчиком. Расстояние от диафрагмы до торца камеры высокого давления (КВД) составляло $540 \mathrm{~mm}$, а до датчиков - $660 \mathrm{~mm}(D 1), 1820 \mathrm{~mm}(D 2)$, $2050 \mathrm{~mm}$ (D3), причем датчик $D 2$ располагался так, что над уровнем этого датчика был слой песка толщиной $2 \mathrm{~cm}$, а датчик $D 3$ располагался на дне секции насыпных сред (СНС). Нагнетание воздуха в КВД приводит к разрыву диафрагмы из промасленной бумаги, разделяющей КВД и камеру низкого давления. После разрыва диафрагмы в трубе формируется ударная волна, длительность импульса которой определяется расстоянием от диафрагмы до верхнего торца КВД. Исследуемая среда представляла собой водогазонасыщенную насыпку из песчинок, размеры которых находятся в диапазоне от 160 до $650 \mu \mathrm{m}$, среднеарифметический размер $390 \mu \mathrm{m}$ (фотография с гистограммой приведена в [8]), пористость 31.5 , плотность уплотненного песка $1600 \mathrm{~kg} / \mathrm{m}^{3}$, водонасыщенность определялась как отношение объема воды к общему объему пор.

Первоначально был изучен результат воздействия ударной волны на высушенный в вакуумном шкафу песок (рис. 1,a). После разрыва диафрагмы в камере низкого давления формируется ударная волна, которая распространяется сверху вниз (рис. 1, $a$, эпюра 1), воздействует на насыпную среду, отражается от ее поверхности и распространяется вверх (эпюра $1 r$ ), далее отражается от верхнего торца КВД и распространяется сверху вниз переотраженная волна (эпюра 2), таким же образом формируется вторая переотраженная волна (эпюра 3). Амплитуда давления падающей волны (эпюра 1) составляет $16 \mathrm{kPa}$, длительность импульса $2.5 \mathrm{~ms}$, скорость распространения в ударной трубе $350 \pm 10 \mathrm{~m} / \mathrm{s}$. Отметим, что при отражении волны от поверхности насыпной среды появляются осцилляции порядка $30 \%$ от амплитуды первоначального сигнала с частотой порядка $23 \mathrm{kHz}$ (эпюра $1 r$ ), которые при переотражении слегка уменьшаются. Амплитуда переотраженной волны составляет $13 \mathrm{kPa}$ (эпюра 2), ее осцилляции в верхнем слое насыпки гасятся (эпюра $2 r$ ). Падающий импульс ударной волны (эпюра 1), проходя через слой сухого песка, несколько изменяет свою форму, передний фронт импульса становится более крутым. Обозначим крутизну 
фронта через $P_{i}=(\Delta p / \Delta t)_{\max }[\mathrm{kPa} / \mathrm{s}]$, где $i$ соответствует выбранной эпюре, тогда крутизна фронта падающей волны $P_{1}=36 \mathrm{kPa} / \mathrm{s}$, а для импульса, прошедшего слой, $P_{1 a}=55 \mathrm{kPa} / \mathrm{s}$, его амплитуда составляет 0.7 от амплитуды падающего импульса, задний фронт растягивается, наблюдается остаточное давление приблизительно $1 \mathrm{kPa}$. Зондирующий импульс приходит на границу песка через $13 \mathrm{~ms}$ после начала воздействия ударного импульса, через $9 \mathrm{~ms}$ после прохождения его заднего фронта. Крутизна фронта зондирующего импульса $P_{2}=340 \mathrm{kPa} / \mathrm{s}$ (эпюра 2) больше, чем в случае падающего импульса (эпюра 1), но, когда он проходит слой песка, происходит преобразование его формы, начальная крутизна $P_{2 a}=6 \mathrm{kPa} / \mathrm{s}$ (эпюра $2 a$ ) плавно уменьшается, что свидетельствует о разрыхлении среды в результате воздействия падающей волны. В дальнейшем формируется резкий пик через $3.3 \mathrm{~ms}$ от начала формирования сигнала на датчике $D 2$, его амплитуда на треть превышает амплитуду импульса от падающей волны (эпюры $1 a, 2 a$, датчик $D 2)$. Задний фронт менее пологий, чем у падающего, остаточное давление составляет $2 \mathrm{kPa}$.

Для объяснения формирования пика (эпюра $2 a$ ) можно предложить следующую физическую модель. Под давлением импульса сжатия насыпная среда сжимается пока есть импульс избыточного давления (эпюра 1). После прохождения импульса происходит разгрузка, верхний слой насыпки после сжатия релаксирует, „расширяясь“ в течение $10 \mathrm{~ms}$. При прохождении импульса переотраженной волны через „разрыхленный“ слой частицы песка ускоряются, к моменту завершения импульса „натыкаются““ на менее возмущенный слой, их торможение приводит к образованию пика давления на фоне импульса. Если рассматривать в качестве зондирующего и второй переотраженный импульс (эпюра 3), то видно, что после воздействия двух предыдущих импульсов (эпюры 1 и 2) слой песка перед вторым датчиком еще более разрыхляется, на что указывает уменьшение крутизны фронта $\left(P_{3 a}=4.5 \mathrm{kPa} / \mathrm{s}\right)$ и более позднее образование пика (эпюра $3 a$ ). Отметим, что двухсантиметровый слой насыпки кардинально изменяет форму импульса при прохождении переотраженных волн, тогда как на донных датчиках после прохождения всего слоя насыпки как от падающей, так и от зондирующей волны формируется ступенчатый сигнал с осцилляциями (эпюры $1 b, 2 b, 3 b$ ).

Особо следует выделить влияние динамических характеристик песчаной насыпки, которые проявляются при воздействии ударной волны. Ударный импульс при прохождении двухсантиметрового слоя практически сохраняет свою форму (эпюра $1 a$ ), через толщу песка проходят лишь осцилляции частотой $1.7 \mathrm{kHz}$ с амплитудой $1 \mathrm{kPa}$ (эпюра $1 b$ ) со ступенчатым ростом $1 \mathrm{kPa}$. Энергия ударного импульса, по всей видимости, частично перешла в кинетическую энергию песка, песчинки по инерции продолжают двигаться вниз и давить на донный датчик. Толща песка сжимается в течение $4 \mathrm{~ms}$, далее сжатая „пружинка“ разжимается, деформированные песчинки расправляются, отталкиваются друг от друга, насыпка становится более рыхлой по сравнению

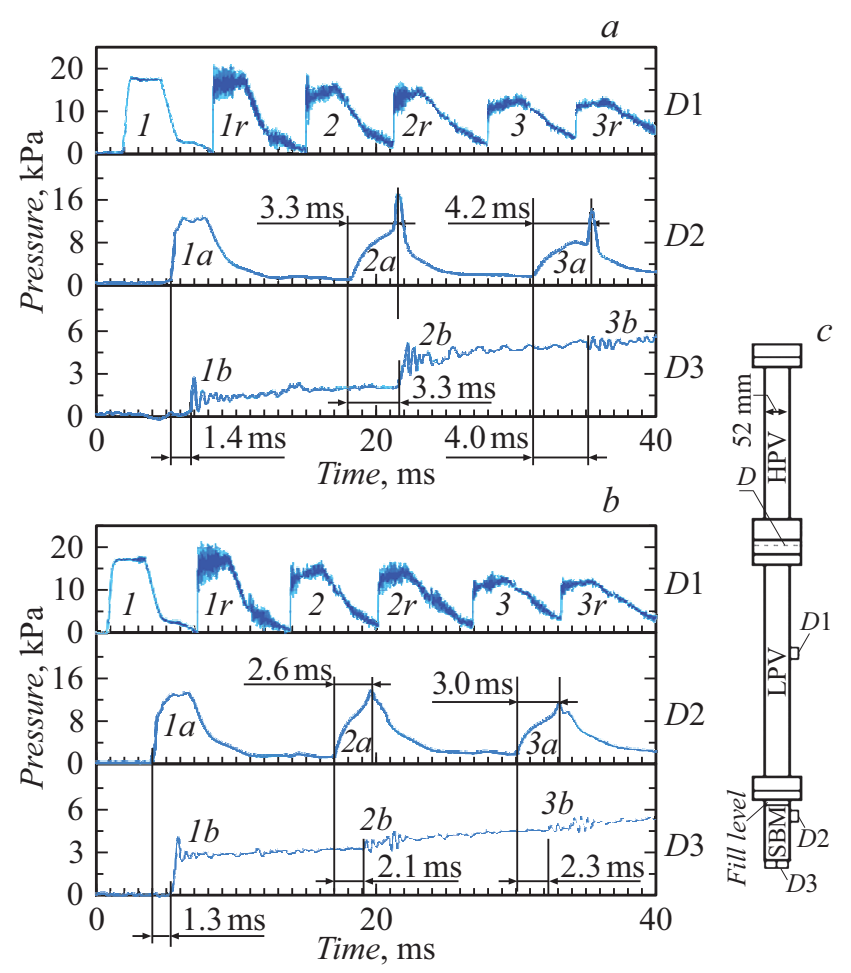

Рис. 1. Осциллограммы давления на пьезоэлектрических датчиках от ударной волны и ее переотражений при водонасыщенности $0(a)$ и $4 \%(b)$. На вставке - схематическое изображение датчиков в камере низкого давления и в секции насыпных сред. HPV - камера высокого давления, LPV — камера низкого давления, SBM - секция насыпных сред, $D$ - диафрагма, $D 1, D 2, D 3$ - пьезометрические датчики, fill level - уровень насыпки. Эпюры $D 1, D 2, D 3$ соответствуют показаниям датчиков LP1, LP2, LP3. Здесь и далее приведены временны́е интервалы, характеризующие время прохождения импульса через толщу насыпки, а также временны́е интервалы, указывающие время образования пика от начала импульса.

с исходным состоянием, и все это, видимо, сказывается на поведении зондирующего импульса: он идет по более рыхлой среде, поэтому скорость переотраженных волн в толще песка меньше скорости падающей волны почти в 2.5 раза. Отметим, что скорость рассчитывается как средняя на участке между датчиками $D 2$ и $D 3$.

Наличие небольшой влажности песка (4\%) приводит к заметным изменениям эпюр давления (рис. $1, b)$ : фронт нарастает немного быстрее, чем в случае сухого песка (эпюра 2a). При прохождении слоя песка формируется пик, как и в сухом песке, но его формирование происходит за более короткое время, амплитуда пика уменьшается, крутизна $P_{2 a}=9 \mathrm{kPa} / \mathrm{s}$ возрастает. Существенное отличие от случая сухого песка состоит в том, что на донный датчик приходит ступенчатый сигнал вдвое большей амплитуды с осцилляциями $1.8 \mathrm{kHz}$, от зондирующих импульсов ступенька не образуется, есть небольшие осцилляции $2.3 \mathrm{kHz}$. Таким образом, прохождение зондирующего импульса показывает, что незначительная влажность (4\%) делает структуру системы более устойчивой к ударному воздействию. 

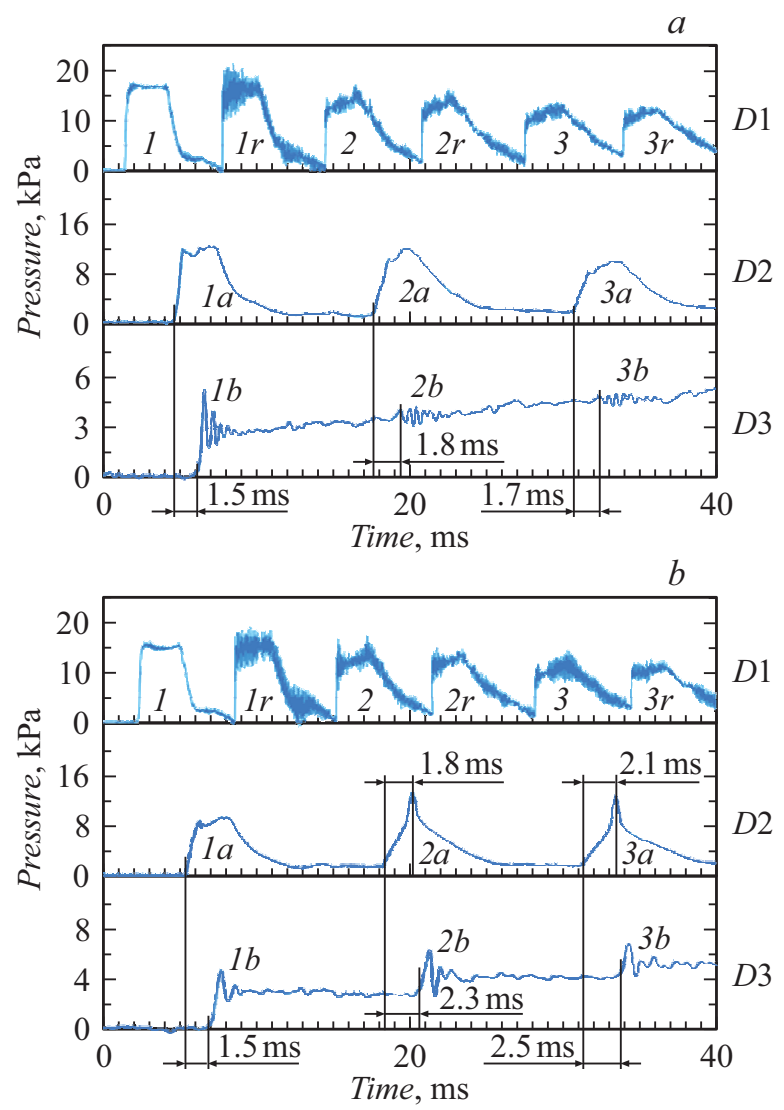

Рис. 2. Осциллограммы давления на пьезоэлектрических датчиках от ударной волны и ее переотражений при водонасыщенности $10(a)$ и $60 \%(b)$. Эпюры $D 1, D 2, D 3$ отвечают показаниям соответствующих датчиков.

При водонасыщенности $10 \%$ (рис. 2,a) крутизна фронта на втором датчике $P_{1 a}=34 \mathrm{kPa} / \mathrm{s}$ уменьшается (эпюра 1a). Амплитуда сигнала от зондирующего импульса (эпюра 2a) практически такая же, как амплитуда падающей волны, пик исчезает (эпюра 2a). Под воздействием ударной волны изменение структуры верхнего слоя насыпки становится существенно меньше, хотя оно присутствует, о чем свидетельствует уменьшение крутизны фронта $P_{2 a}=14 \mathrm{kPa} / \mathrm{s}$ (эпюра $2 a$ ) по сравнению с крутизной импульса от падающей волны $P_{1 a}=34 \mathrm{kPa} / \mathrm{s}$. На донном датчике $(D 3$, эпюра $1 b)$ появились осцилляции с частотой $1.8 \mathrm{kHz}$ значительной амплитуды, вдвое превышающей значение, полученное при влажности $4 \%$. Таким образом, изменение верхнего слоя незначительно, а на донном датчике зондирующий импульс дает практически такой же сигнал, как и при $4 \%$. Увеличение влажности до $10 \%$ дает еще более устойчивую структуру, приводит к увеличению проходимости падающей ударной волны, в то время как зондирующий импульс практически не проходит, поглощается всей толщей насыпки.

При водонасыщенности $60 \%$ (рис. $2, b$ ) фронт ударного импульса, прошедшего двухсантиметровый слой (эпюра $1 a$ ), становится еще более пологим $\left(P_{1 a}=20 \mathrm{kPa} / \mathrm{s}\right)$, амплитуда снижается по сравнению со случаем падающей волны до 0.5. Фронт от зондирующего импульса становится более пологим $\left(P_{2 a}=7 \mathrm{kPa} / \mathrm{s}\right)$, чем при водонасыщенности $10 \%$, но от зондирующего импульса на датчике $D 2$ проявляется импульс с пиком (эпюра 2a), который указывает на то, что после воздействия ударной волны возникли структурные преобразования в верхнем слое насыпки. Пики давления на эпюрах $2 a$ и $3 a$ образуются в начальной части импульса в отличие от сухого песка, и их образование, по всей видимости, связано с изменением структуры распределения газа в поровом пространстве газоводонасыщенной среды. Можно предположить, что из бесформенных газовых кластеров после „встряски“ под действием ударной волны образуются газовые пузырьки под действием капиллярных сил. Эпюра второго зондирующего импульса (эпюра $3 a$ ) показывает, что воздействие зондирующего импульса (эпюра $2 a$ ) практически никакого изменения в структуру пузырьковой среды не вносит. Картина сигналов на донном датчике существенно отличается от всех предыдущих случаев: 1) частота осцилляций уменьшается в 1.5 раза $(1.2 \mathrm{kHz}) ; 2)$ после падающего и зондирующего импульсов уровень сигнала возрастает ступенчато, между импульсами давление не нарастает, как было ранее.

Для получения водонасыщенности 100\% СНС заполнялась водой, далее в воду мелкими порциями засыпался песок, излишек воды убирался, после такого заполнения проводилось воздействие ударной волной. Импульс на втором датчике практически вдвое превышает амплитуду падающего импульса (рис. $3, a$, эпюра $1 a$ ), что объясняется удвоением амплитуды ударной волны, как при отражении от „жесткой стенки“, роль которой выполняет насыпная среда с полностью водонасыщенными порами и малым поглощением энергии импульса в двухсантиметровом слое. На донном датчике наблюдаются небольшие осцилляции, частота которых $1.7 \mathrm{kHz}$ значительно выше частоты осцилляций при $60 \%$, после воздействия ударной волны зондирующий импульс хорошо проходит через толщу песка. Скорость ударной волны в песке, полностью насыщенном водой, была на порядок ниже скорости звука в воде. Мы предположили, что это связано с наличием микропузырьков. Полученная при этом скорость $160 \mathrm{~m} / \mathrm{s}$ соответствует объемному содержанию газа в воде без песка порядка $0.3 \%$ [8].

Для того чтобы избавиться от микропузырьков, насыпка, залитая водой, в лотках помещалась в вакуумную камеру, дегазировалась, далее перемещалась в CHC. Эпюры, соответствующие прохождению волны в насыпной среде, насыщенной дегазированной водой, качественно отличаются от всех предыдущих (рис. $3, b$ ). Передний фронт импульсов на датчике $D 2$ становится круче, импульсы характеризуются высокочастотными колебаниями на фронте (эпюры $1 a, 2 a, 3 a$ ) порядка $25 \mathrm{kHz}$. На донном датчике формируются сглаженные импульсы, четко соответствующие падающему (эпюра $1 b$ ) и двум переотраженным (эпюры $2 b, 3 b$ ). Значительное снижение количества микропузырьков приводит к увеличению акустической жесткости среды. Скорость прохождения 

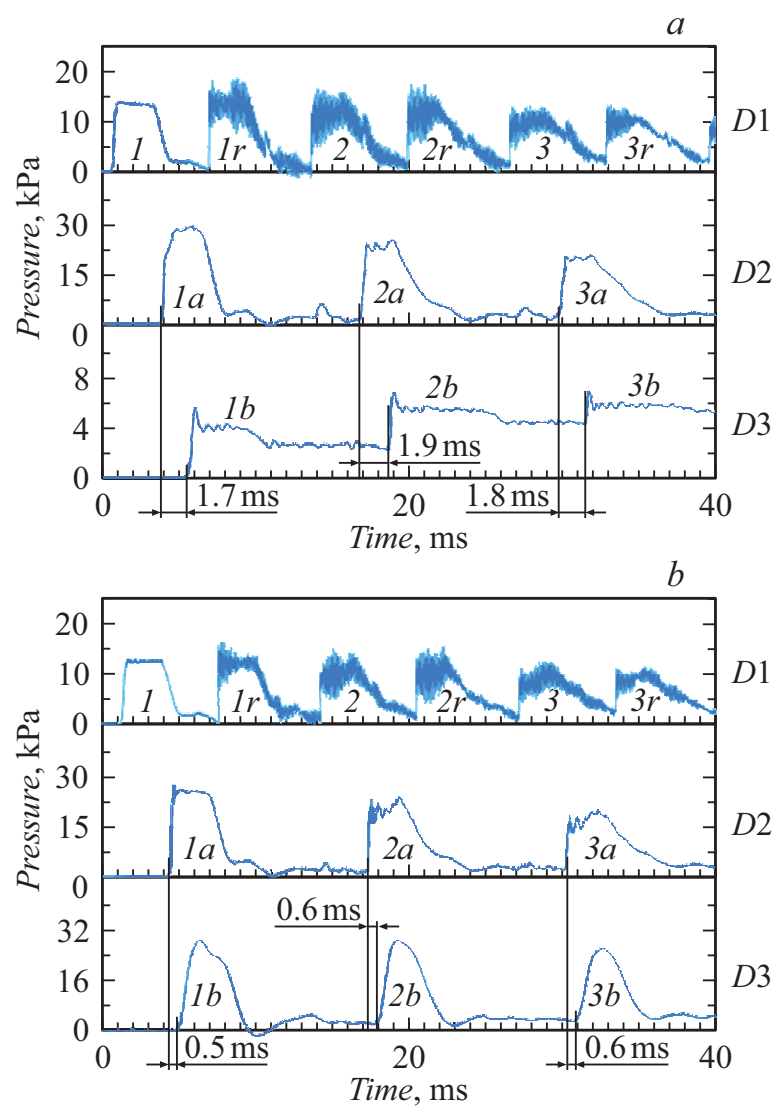

Рис. 3. Осциллограммы давления на пьезоэлектрических датчиках от ударной волны и ее переотражений. $a-$ без дегазации, $b-$ в случае дегазированной жидкости. Эпюры $D 1$, $D 2, D 3$ отвечают показаниям соответствующих датчиков при водонасыщенности $100 \%$.

волны многократно возрастает (более чем в 3 раза), степень возрастания зависит от степени дегазации [9]. На донном датчике в результате воздействия ударных и зондирующих импульсов образуются близкие по форме эпюры (эпюры $1 b, 2 b, 3 b)$. Это свидетельствует о том, что в однородной среде, свойства которой не изменяются при воздействии ударной волны, оба зондирующих импульса проходят практически так же, как и падающий импульс, это подтверждает правомерность использования переотраженных волн в качестве зондирующих импульсов для изучения изменений, происходящих после воздействия ударной волны на водогазонасыщенную насыпную среду.

Использованный способ зондирования насыпных сред с целью определения изменения их волновых свойств непосредственно после $(10 \mathrm{~ms})$ воздействия ударной волны с помощью переотраженных волн позволил установить существенное изменение свойств насыпных сред при воздействии ударных волн даже небольшой интенсивности (менее $20 \mathrm{kPa}$ ). Наиболее яркие изменения наблюдаются в сухой насыпке и при водонасыщенности 60 и $100 \%$.

В заключение можно отметить, что использование зондирующих импульсов позволило обнаружить измене- ния, произошедшие непосредственно после воздействия ударной волны:

1) в сухом песке формирование пика на глубине $2 \mathrm{~cm}$ от поверхности и более чем двукратное уменьшение скорости зондирующего импульса по сравнению со скоростью падающей ударной волны;

2) при влагосодержании 4 и 10\% зондирующий импульс поглощается значительно сильнее, чем в случае сухого песка;

3) для водонасыщенности 60\% имеет место формирование пика и уменьшение скорости в 1.5 раза по сравнению со скоростью падающей ударной волны, скорее всего из-за образования пузырьков.

Установлено огромное влияние микропузырьков на прохождение зондирующих импульсов сквозь толщу стопроцентно водонасыщенной насыпной среды, дегазация приводит к сохранению формы импульсов и многократному увеличению скорости ударной волны.

\section{Благодарности}

В работе использовано оборудование РЦКП „Агидель“ УФИЦ РАН.

\section{Финансирование работы}

Исследование выполнено за счет средств государственного бюджета по госзаданию на 2019-2022 гг. (№ 0246-2019-0052) и в рамках госзадания в сфере научной деятельности № FEUR-2020-0004 („Решение актуальных задач и исследование процессов в нефтехимических производствах, сопровождающихся течениями многофазных сред“).

\section{Конфликт интересов}

Авторы заявляют, что у них нет конфликта интересов.

\section{Список литературы}

[1] Г.М. Ляхов, Основы динамики взрыва в грунтах и горных nopodax (M., 1974).

[2] Д.М. Балапанов, С.Ф. Урманчеев, Письма в ЖТФ, 36 (13), $71(2010)$

[3] И.К. Гималтдинов, Л.Ф. Ситдикова, В.Л. Дмитриев, Т.М. Левина, Н.C. Хабеев, W. Song, Инж.-физ. журн., 90 (5), 1098 (2017).

[4] А.Т. Ахметов, А.А. Губайдуллин, Д.Н. Дудко, Изв. вузов. Нефть и газ, № 1, 30 (1999).

[5] A.A. Gubaidullin, A. Britan, D.N. Dudko, Shock waves, 13 (1), 41 (2003). DOI: 10.1007/s00193-003-0193-2

[6] A.A. Gubaidullin, O.Yu. Boldyreva, D.N. Dudko, J. Phys.: Conf. Ser., 899, 032011 (2017). DOI: $10.1088 / 1742-6596 / 899 / 3 / 032011$

[7] В.Е. Донцов, Изв. РАН. Механика жидкости и газа, № 1, 80 (1992).

[8] Р.И. Нигматулин, Динамика многофазных сред (Наука, М., 1987), ч. 2.

[9] А.Т. Ахметов, И.К. Гималтдинов, Л.Ф. Ситдикова, М.Ш. Азаматов, Ю.С. Султангареев, Т.Д. Хайретдинов, Инж.-физ. журн., № 2, 418 (2021). 